\title{
A Photo-electric Visibility Meter
}

\author{
By J. R. Bibby \\ Meteorological Office, Air Ministry, Harrow, England \\ (Manuscript received 12 June 1957)
}

\section{Historical}

The British Meteorological Office began development of photo-electric equipment for measuring visibility in 1943, with the object of obtaining more accurate information on the distance at which runway lights would be visible to an aircraft about to land. Early work showed promise of success, and led to the manufacture of twenty photo-electric Visibility Meters (Mark I). Trials of these at 15 stations during 1949 showed various ways in which improvements could be made, and a redesigned instrument (Mark II) was installed at London Airport in March 1951, and has been operating ever since. Several others have been made in the Meteorological Office workshop for fog investigations, chiefly at Cardington.

\section{Description}

The principle used is to measure the attenuation of a horizontal beam of light over a distance of about 300 yards. The beam is formed by a small projector, adapted from a Naval signalling lamp (Fig. 1). It

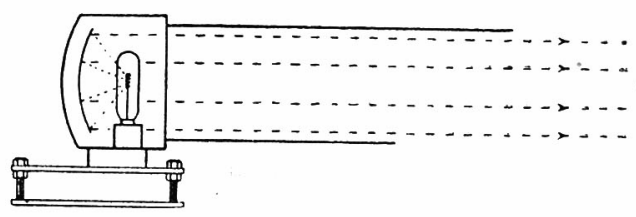

Fig. 1

has a parabolic mirror $5 \frac{1}{2}$ ins. diameter, $2 \frac{1}{2}$ ins. focal length. A "solid source" lamp (24 volts 240 watts) is used to give a beam which is sensibly uniform over several degrees, so that very accurate alignment on the receiver is not necessary. The projector is mounted on an adjustable base, and is fitted with a hood to keep rain off the front glass. Power for the lamp is provided by a transformer giving a nominal 24 volts; its primary is supplied from A. C. mains through a "Variac", by means of which the voltage applied to the lamp can be varied.

At a point about 300 yards from the lamp, the intensity of the beam is measured by means of a photocell (selenium barrier layer type, $25 \mathrm{~mm}$ diameter). It is at one end of a long cylindrical housing (Fig. 2)

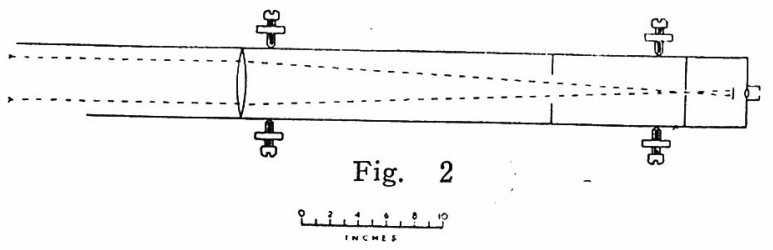

behind a screen in which is a hole $3 / 16$ ins. diameter. This hole is at the focus of a convex lens (5 ins. diameter, 31 ins. focal length) at the other end of the housing. This arrangement ensures that very little daylight reaches the photocell. To keep the lens dry, a rain shield is fitted in front of it, and also a small electric heater consisting of lengths of fine wire stretched across the lens a little way behind it. A silica-gel drier is placed in the housing, at the photocell end. The housing is mounted on adjusting screws for accurate alignment on the projector. To facilitate this, the photocell can be moved to one side, allowing observation through a small lens, which forms a telescope with the main lens.

The photocell current could be measured 


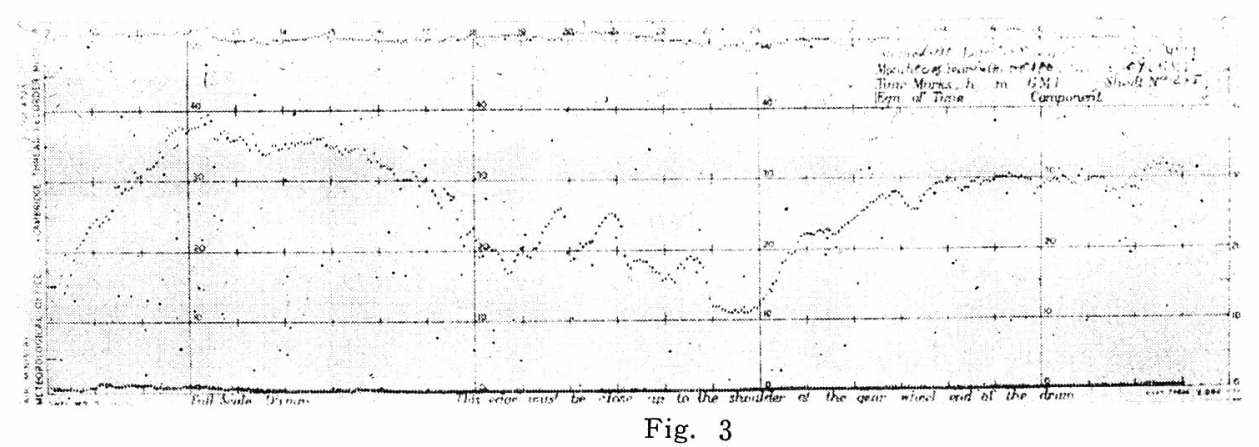

by a simple mirror galvanometer, but it is more convenient to use a recorder. That at London Airport is a Cambridge Thread recorder (full scale deflection $5 \mu \mathrm{A}$, resistance $2000 \mathrm{ohms}$ ). It makes a dot each minute, and works on a four minute cycle as follows:

1st and 2nd minute: photocell current with projector lamp off (this is to give a correction for any day light which may reach the photocell.

3rd minute: photocell current with projector switched on (by an automatic switch in the recorder).

4th minute: Record of mains voltage, obtained via a small transformer, rectifier, and resistance network including a variable resistance for adjusting the record as required.

A typical record is shown in Fig. 3. The lowest trace is the effect of daylight, which is always very small. The middle trace is the photocell current with projector on, and is adjusted (by means of the Variac) so that it reads 45 on the scale in extremely good visibility. The top trace shows variations in mains voltage, and should be set (by means of the variable resistance) so that it reads exactly 50 when the mains voltage has its normal value.

\section{Interpretation of the records}

The middle trace on the record indicates the visibility, but it must be corrected as follows:

(a) If the lowest trace is not zero, its value is deducted from the middle trace. (b) If the top trace is not on the 50 line, the middle trace is increased (decreased) by $6 \%$ for every unit by which the voltage trace is below (above) 50 . This is based on the experimental finding that the lamp brightness varies approximately as the cube of the voltage.

The corrected value of the middle trace is then used to obtain the visibility from a table, of which an abridged version is given in Table 1.

The basis of this table is as follows. The extinction coefficient of the air, $\sigma$, is given by

$$
I=I_{o} e^{-\boldsymbol{\sigma} d}
$$

where $\mathrm{I}$ is the galvanometer reading (i. $e$. the middle trace, corrected); $I_{0}$ the reading if the atmosphere was perfectly transparent, which is taken as 45 on the charts used at London Airport; $d$ is the distance between projector and photocell unit, 280 yards at London Airport.

The visibility $V$ is then obtained from Koschmieder's equation

$$
\sigma V=-\log _{e} E
$$

where $E$ is the threshold contrast which the eye can just perceive in daylight. $E$ has usually been taken as 0.02 , whence $\sigma V=3.91$; but as this applies to completely black objects, the table is based on $\sigma V=3.75$, as it was expected that this would give better agreement with the visibility of ordinary objects.

\section{Results obtained at London Airport}

Two years records (1954-55) have been analysed to find out how closely the meter 
readings agree with the visibility as ordinarily observed. Hourly observations, during daylight only, were used. A correction was first applied to the readings, however, for the following reason: as indicated above, slow changes in lamp brightness and photocell sensitivity can be allowed for by adjusting the Variac to bring the middle trace to the right visibility reading, then adjusting the variable resistance to bring the voltage reading to the 50 line. Ideally this should be done on every occasion of good visibility, but was actually only done fairly infrequently (because the instrument is useful more as indicating changes of visibility than absolute values).

A retrospective adjustment was therefore made as follows: on each occasion of visibility 10 miles or more, a factor was calculated, by which the galvanometer reading should be multiplied to bring it to the correct reading for the observed visibility. The average of these factors obtained for any particular day was used to multiply the readings for subsequent days, until another day of good visibility enabled another factor to be obtained. The factors were mostly between 0.95 and 1.15 , and it was unusual for successive factors to differ by more than 0.1. A few exceptionally large changes occurred, some of which were probably due to adjustments of the controls or replacement of the lamp, but no complete record of these has been kept. As an example, the factors for the second half of 1954 are shown in Fig. 4.

ADJUSTMENT FACTORS (see para.4)

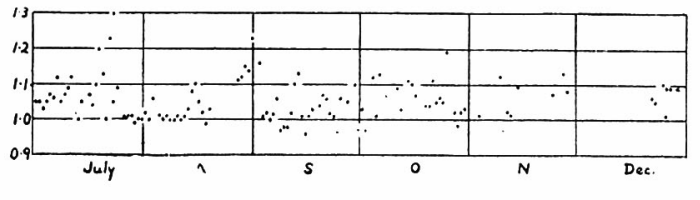

Fig. 4

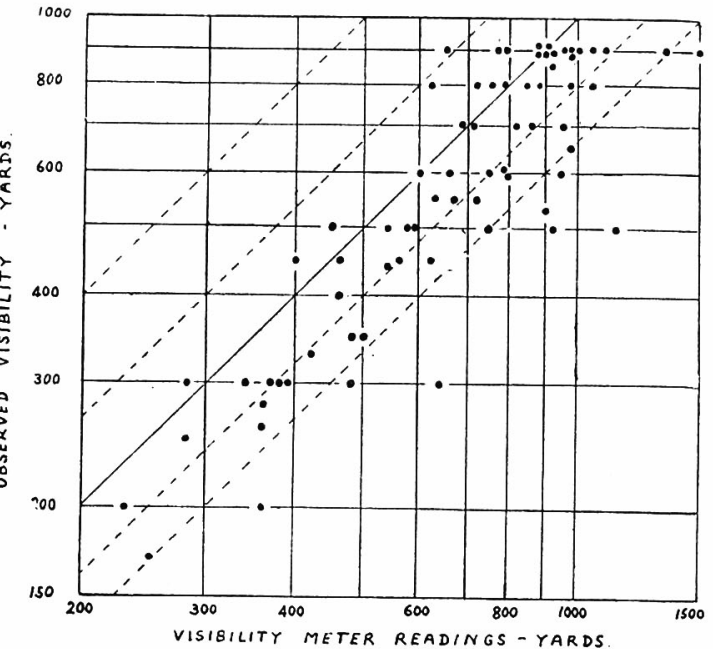

Fig. 5

Whenever the observed visibility was 3000 yards or less, the meter reading was multiplied by the factor, as indicated above, the corresponding visibility determined, and plotted on a graph of measured visibility against observed visibility. The part of the graph for observed visibilities below 1000 yards is shown in Fig. 5. These observations have been considered separately, for the following reasons:

(a) They cover the range of greatest importance to aviation.

(b) Variations of lamp brightness and photocell sensitivity (i.e. uncertainty in the correction factor) have relatively little effect in this visibility range, as can be seen from Table 1 .

(c) The 280 yard path sampled by the instrument is more likely to be representative of the atmosphere observed visually.

Only 70 useful observations below 1000 yards occurred in the two years. This is partly because those below about 250 yards give zero reading on the recorder and partly because many occasions with visibility in the required range occurred during the onset or clearance of $f o g$, when

Table 1

\begin{tabular}{lrrrrrrrrrr} 
Galvanometer & 1 & 5 & 10 & 15 & 20 & 25 & 30 & 35 & 40 & 44 \\
Visibility & 280 & 480 & 700 & 950 & 1300 & 1750 & 2600 yds. $2 \frac{1}{4}$ & $4 \frac{1}{2}$ & 20 miles \\
\hline
\end{tabular}


Table 2

\begin{tabular}{|c|c|c|c|c|c|c|c|c|c|}
\hline \multirow[b]{2}{*}{ Visibility range } & \multicolumn{6}{|c|}{$\begin{array}{l}\text { Percentage of readings differing from the } \\
\text { observed visibility by the following amounts: }\end{array}$} & \multicolumn{3}{|c|}{ Percentage of readings with: } \\
\hline & $\begin{array}{l}\text { more } \\
\text { than } \\
-50 \%\end{array}$ & $\begin{array}{l}-50 \% \\
\text { to } \\
-25 \%\end{array}$ & $\begin{array}{l}-25 \% \\
\text { to } \\
0 \%\end{array}$ & $\begin{array}{l}0 \% \\
\text { to } \\
+25 \%\end{array}$ & $\begin{array}{l}+25 \% \\
\text { to } \\
+50 \%\end{array}$ & $\begin{array}{l}\text { more } \\
\text { than } \\
+50 \%\end{array}$ & $\begin{array}{l}\text { differences } \\
\text { less than } \\
\pm 25 \%\end{array}$ & $\begin{array}{l}\text { differences } \\
\pm 25 \% \text { to } \\
\pm 50 \%\end{array}$ & $\begin{array}{l}\text { differences } \\
\text { over } \\
\pm 50 \%\end{array}$ \\
\hline $\begin{array}{l}\text { Less than } 1000 \\
\text { yards } \\
\text { (70 readings) }\end{array}$ & 0 & 1 & 17 & 44 & 24 & 13 & 61 & 25 & 13 \\
\hline $\begin{array}{l}\text { As above, but } \\
\text { meter visibilities } \\
\text { reduced by } 14 \%\end{array}$ & 0 & 4 & 46 & 33 & 11 & 6 & 79 & 15 & 6 \\
\hline $\begin{array}{l}1000-3000 \text { yards } \\
\text { inclusive } \\
(279 \text { readings })\end{array}$ & 2 & 6 & 23 & 33 & 17 & 20 & 56 & 23 & 22 \\
\hline $\begin{array}{l}\text { As above, but } \\
\text { meter visibilities } \\
\text { reduced by } 12 \%\end{array}$ & 3 & 13 & 33 & 28 & 11 & 12 & 61 & 24 & 15 \\
\hline
\end{tabular}

visibility was varying so rapidly that comparisons would be misleading because of possible timing errors.

The 70 observations are shown on Fig. 5 , the coordinates being on logarithmic scales. The diagonal full line indicates equality between measured and observed visibility, and the broken lines indicate differences between measured and observed visibility of $\pm 25 \%$ and $\pm 50 \%$. The percentage of the observations with differences in each category is shown on the first line of Table 2. In the last three columns of the table the positive and negative differences are combined.

It is clear from Fig. 5 that in most cases the meter indicates a visibility greater than is observed by eye. An improvement would result if the meter visibilities were all reduced in the same proportion. To give equal numbers of positive and negative differences a reduction of $14 \%$ is needed, and the result of doing this is shown in the second line of Table 2 .

The third line of Table 2 gives the result of a similar analysis of the 279 readings when the observed visibility was from 1000 to 3000 yards inclusive. (All higher visibilities were ignored, as small changes in lamp brightness, etc., would have a big effect on the accuracy of the meter). Again it is seen that positive differences predomi- nate, and a reduction of $12 \%$ was needed to equalise the number of positive and negative ones. The result of doing this is given in the fourth line of the table.

\section{Discussion of results}

Table 2 confirms the expectation that meter readings would show better agreement with observed visibility below 1000 yards.

In considering the figures it must be remembered that eye estimates of visibility are hardly accurate to better than $15 \%$ even in good conditions, and that differences of about $10 \%$ in the visibility in different directions are probably quite common. Thus even if the visibility meter was perfect, differences from the observed visibility of up to $25 \%$ would be commonplace. If corrections are applied as indicated above, differences are less than $25 \%$ in $79 \%$ of occasions with visibility below 1000 yards, and $61 \%$ of occasions between 1000 and 3000 yards. The performance of the instrument can be considered satisfactory in these cases, inasmuch as a perfect instrument would show equally large differences.

Differences over $25 \%$ may be due to instrument errors, or to exceptionally large errors of observation by eye, or exceptionally large variations of visibility over short distances. The relative importance of these 
can only be conjectured, but several reasons suggest that large instrumental errors are infrequent.

First, the largest differences amount to a factor of about two below 1000 yards and three in the range 1000 to 3000 yards. These roughly correspond to the galvanometer reading being wrong by a factor of two. But Fig. 4 shows the general consistency of the galvanometer readings, and makes such large errors appear unlikely.

As a check on this point, two visibility meters were set up side by side and compared over a month. The ratio of their readings only varied by $\pm 6 \%$.

Finally, in the majority of cases of large discrepancies the visibility meter gives the higher value, whereas the more obvious instrumental defects would make it read too low.

Occasional gross errors of observing may be possible, not only through carelessness, but also because of the small size and light colour of some of the visibility objects, probably made worse at times by uneven illumination, e. g. in partly cloudy conditions. But atmospheric inhomogeneity may well account for most of the big differences, even though one end of the instrument light path is near the observation point. There are several large buildings just to one side of the light path, which might be expected to change the extinction coefficient of the adjacent air on occasions.

\section{Conclusions}

(1) This instrument is capable of continuous operation by persons without special experience of instruments (the need for repairs or adjustment by the Instruments Branch has not occurred oftener than once or twice a year).

(2) The table for converting meter reading to visibility should be revised, reducing the visibilities by $13 \%$ (the mean of the two values in Table 2). This is equivalent to using the equation $\sigma V=3.25$ instead of 3.75 , and corresponds to a contrast threshold of 0.039 instead of 0.02 previously assumed. (It may be noted that the W. M. O. has recommended that a contrast threshold of 0.05 should be adopted).

(3) Provided the proper adjustments are made on every occasion of good visibility, the readings should be within $25 \%$ of eye estimates made nearby on about $80 \%$ of occasions with visibility below 1000 yards, and about $60 \%$ of occasions with visibility between 1000 and 3000 yards.

(4) Most cases of lower accuracy can probably be accounted for by atmospheric inhomogeneity. This points to the need for installing the instrument at the exact place where the visibility is required, rather than improvements in the instrument itself.

(5) It would probably be worth the extra expense to provide a voltage stabiliser for the projector lamp. This should eliminate the voltage correction and allow the charts to show the visibility directly. 